AperTO - Archivio Istituzionale Open Access dell'Università di Torino

\title{
Viability and germinability in long term storage of Corylus avellana pollen
}

\section{This is the author's manuscript}

Original Citation:

Availability:

This version is available http://hdl.handle.net/2318/1627258

since 2017-03-03T16:33:25Z

Published version:

DOI:10.1016/j.scienta.2016.11.042

Terms of use:

Open Access

Anyone can freely access the full text of works made available as "Open Access". Works made available under a Creative Commons license can be used according to the terms and conditions of said license. Use of all other works requires consent of the right holder (author or publisher) if not exempted from copyright protection by the applicable law. 
This Accepted Author Manuscript (AAM) is copyrighted and published by Elsevier. It is posted here by agreement between Elsevier and the University of Turin. Changes resulting from the publishing process - such as editing, corrections, structural formatting, and other quality control mechanisms - may not be reflected in this version of the text. The definitive version of the text was subsequently published in SCIENTIA HORTICULTURAE, 214, 2017, 10.1016/j.scienta.2016.11.042.

You may download, copy and otherwise use the AAM for non-commercial purposes provided that your license is limited by the following restrictions:

(1) You may use this AAM for non-commercial purposes only under the terms of the CC-BY-NC-ND license.

(2) The integrity of the work and identification of the author, copyright owner, and publisher must be preserved in any copy.

(3) You must attribute this AAM in the following format: Creative Commons BY-NC-ND license (http://creativecommons.org/licenses/by-nc-nd/4.0/deed.en), 10.1016/j.scienta.2016.11.042

The publisher's version is available at:

http://linkinghub.elsevier.com/retrieve/pii/S0304423816306112

When citing, please refer to the published version.

Link to this full text:

http://hdl.handle.net/2318/1627258 


\title{
Viability and germinability in long term storage of Corylus avellana pollen
}

\author{
Cristina Novara a,*, Lorenzo Ascari a, Valentina La Morgia b, Luisella Reale a, Andrea Genre a, \\ Consolata Siniscalco a \\ a Department of Life Sciences and Systems Biology, University of Turin, Viale Mattioli, 25, 10125 Torino, Italy \\ b ISPRA, Italian National Institute for Environmental Protection and Research, via Ca' Fornacetta 9, 40064, Ozzano dell'Emilia (BO), Italy
}

\begin{abstract}
a b s t r a c t
European hazel is one of the most important fruit tree crop in the world and since the demand of nuts is growing, the cultivation area of this species has extended outside its native range. Many hazel cultivars are self-incompatible and the flowering period of male and female flowers in different cultivars only partially overlaps, so hazel requires genetically compatible pollinizer cultivars in order to obtain a good yield For these difficulties and since the male and female flowering can vary from year to year in response to climate variability, artificial or supplementary pollination can be used to improve the final yield and optimize the cross-pollination, in particular outside the native range, where the wild type is absent. Therefore, the aim of this work is to evaluate the best temperature conditions $\left(20,4,-30{ }^{\circ} \mathrm{C}\right)$ for a long-term storage of pollen in order to maintain a high viability level. Pollen coming from three cultivars (Tonda Gentile delle Langhe, Tonda di Giffoni and Tonda Gentile Romana) and wild hazel were collected during two winters. Several methods (in vitro pollen germination, 2,3,5-triphenyltetrazolium chloride test, fluorescein diacetate and propidium iodide solution) were used to obtain a reliable estimation of pollen viability and germinability. All methods, although highlighting differences among cultivars, demonstrated that the $30 . \mathrm{C}$ temperature storage condition is the best in order to maintain a high viability level $(>40-50 \%)$ at 150 days from harvesting.
\end{abstract}

\section{Introduction}

European hazel, Corylus avellana L. (Betulaceae), is one of the most important fruit tree crop in the world. This species is monoecious, dichogamous, and wind-pollinated. Worldwide, there are about 400 cultivars mainly selected in Italy, Turkey, USA and Spain (Mehlenbacher, 1991) to obtain high-quality nuts useful for industry requirements. The major world producers of hazels are Turkey and Italy with additional production in Azerbaijan, the United States, Georgia, Spain, Iran, China, and France (Food and Agriculture Organization of the United Nations, 2011). Nevertheless, the demand of nuts is growing in all the world and the cultivation area of this species has extended outside its native range, where the natural pollinizers can be absent.

Pollination is one of the most important factors in management of hazel orchards in order to obtain a good yield and reduce blank nuts. However, hazel is self-incompatible and the male and female flowering periods in different compatible cultivars, even if the flow- ering is very long lasting, do not always overlap. Pollen-stigma incompatibility in hazel is of the sporophytic type (Mehlenbacher, 2014) and controlled by a single locus, designated the S-locus, with multiple alleles (haplotypes), and the stigmatic surface is the site of the incompatibility reaction (Thompson, 1979a, 1979b).

For this reason, hazel requires genetically compatible pollinizer cultivar, but pollination remains an uncertain process dependent on numerous factors, such as rainfall, humidity, wind, which can affect this phenomenon in different ways (Ellena et al., 2014; Novara et al., 2016) both during the catkins elongation and pollen dispersion. Moreover, male and female flowering of compatible cultivars should overlap in order to ensure a correct pollination, but flowering can vary from year to year and the response of male and female flowers to interannual variation can be different (Crepins ${ }^{\star} \mathrm{ek}$ et al., 2012; Ellena et al., 2014). For all these reasons, artificial or supplementary pollination can be used to improve the yield.

The aim of the present study is to evaluate the best conditions for long-term hazel pollen storage in order to maintain a high viability level for the use of stored pollen in artificial or supplementary pollination. To this aim, in vitro pollen germination, 2,3,5-triphenyltetrazolium chloride (TTC) and fluorescein diacetate and propidium iodide staining were used to assess a more objective 
estimation of pollen viability. These three methods were compared to assess the germinability and viability of pollen stored at three different temperature conditions $(20,4$ and $-30 \circ \mathrm{C})$ in order to point out the best conditions for long-term conservation during the first 5 months after harvesting.

\section{Materials and methods}

\subsection{Plant materials}

The samplings were performed in 2015 and 2016 winter in hazel orchards located in Langhe Region, Piedmont (Italy), where ten hazel trees for three different cultivars were selected in the field All plants were ten years old, four meters tall, trained to a free vase and $4 \times 4,5 \mathrm{~m}$ spaced. The manual removal of suckers was carried out once a year. The orchard was watered only ones or twice a year, during summer, following necessities. The understory was mowed three times each year. The chemical treatments were only aimed at limiting the hazel gall mite.

Samples of pollen of Tonda Gentile delle Langhe (TGdL), the dominant hazel cultivar (cv.) in north-west Italy, Tonda di Giffoni (TdG), Tonda Gentile Romana (TGR) and wild hazel (WH) were collected during the flowering peak, which varies from the beginning of January for TGdL to the beginning of February for TdG, TGR and the wild type.

The analyzed pollen was collected in the field shaking the catkins directly in sterile Falcon tubes during sunny days, in the central hours of the day in order to collect samples with a low humidity percentage.

\subsection{Storage}

In order to evaluate the best temperature condition for longterm storage to maintain a high pollen viability, three different storage temperature were tested. Pollen was dehydrated over silica gel at room temperature $(20 \circ \mathrm{C})$ and the petri dishes were then sealed and stored at room temperature $(20 \circ \mathrm{C})$, in a fridge at $4{ }^{\circ} \mathrm{C}$ and in a cooled incubator at -30 C. Samples were divided into several aliquots in order to reduce the stress linked to thawing.

\subsection{Pollen viability and germination experiments}

Each test was composed of two repetitions for each sample of TGdL, TdG, TGR and WH pollen, as in other pollen viability tests (Wang et al., 2015). Every repetition had a minimum of 300 analyzed pollen grains. The number of the repetitions and analyzed pollen grains is due to the very high sampling effort.

\subsubsection{TTC pollen viability test}

The TTC experiments were carried out in 2015 and 2016. Pollen was rehydrated by placing the samples in humid chambers for a measured time (60-90 $\mathrm{min}$ ) before performing the tetrazolium test. This test is based on the reduction of soluble colorless tetrazolium salt to reddish insoluble precipitate in the presence of dehydrogenase activity in the pollen grain cells. The pollen grains were incubated in $1 \%$ TTC diluted in a solution of $50 \%$ sucrose (Shivanna, 2003 modified) for $24 \mathrm{~h}$ in dark and humid chambers at room temperature. Following incubation, each sample was observed through the microscope $(250 \times)$ by locating ten random fields and pollen grains that presented a red color were scored as viable. Grains with smaller and different morphology (anomalous grains) were also scored. Each test was repeated every week from the 3rd (or 10th) day for the first month from harvesting and every fifteen-days from the second month for a total of 150 days from harvesting (DfH) for each cultivar and $\mathrm{WH}$.

\subsubsection{In vitro pollen germination}

Preliminary tests were performed to assess the best germination medium. Three different germination substrates were tested: Brewbaker and Kwack (1963), Heslop-Harrison (1988), Potenza et al. (1994).

Two tests were run for each germination medium, including three replicates for each pollen batch. The experiments were carried out in 2016 by using the hanging-drop method (Deng and Harbaugh, 2004; Dutta et al., 2013; Shivanna and Rangaswamy, 1992; Stanley and Linskens, 1974) and the grains were rehydrated before testing. Each sample was observed in brightfield microscopy (Leica DFC420) in ten random fields $(250 \times)$ and scored in order to evaluate the percentage of germinated grains. When the pollen tube length was greater than the diameter of the pollen grain, a germination event was considered. The inclusion of polyethylene glycol (PEG) in the liquid medium improved both pollen germination and tube growth as referred by Calic' et al. (2013), so PEG was used in all our subsequent experiments.

In conclusion, the preliminary tests identified the best germination substrate (Heslop-Harrison, 1988) ad this was used for all the subsequent experiments.

For germination assays, pollen stored at room temperature $(20 \cdot \mathrm{C}), 4 \cdot \mathrm{C}$ and $-30 \cdot \mathrm{C}$ was rehydrated and treated with the same method (hanging-drop) described for the preliminary tests.

For all the cultivars and wild hazel each test was repeated every fifteen-days, for TdG and WH from the 45th to the 115 th day from harvesting, for TGR from the 31 st to the101st day from harvesting and for TGdL from the 66th to the 136th day from harvesting.

\subsubsection{FDA/PI pollen viability test}

The fluorescein diacetate (FDA) test assesses the presence of active esterases in the pollen cytoplasm and the intactness of the plasma membrane (Shivanna and Rangaswamy, 1992). Propidium iodide (PI) is a DNA dye that is generally excluded from viable cells, so it helps to identify dead cells.

TGdL, TGR, TdG and WH pollen was collected in 2016 and was preliminary placed in a humid chamber for $60 \mathrm{~min}$ and then incubated in a $2 \mathrm{mg} / \mathrm{ml} \mathrm{FDA} \mathrm{and} 1 \mathrm{mg} / \mathrm{ml}$ Propidium Iodide (PI) solution in acetone and diluted drop by drop in $100 \quad 1$ of $50 \%$ sucrose solution (Singh et al., 2015).

The pollen samples were centrifuged at $5000 \mathrm{rpm}$ for $1 \mathrm{~min}$; supernatant was discarded and 5 rinses were done in phosphatebuffered saline (PBS). The pollen was finally suspended in $50 \quad 1$ PBS

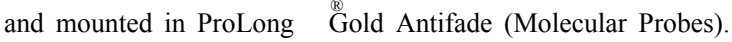

Pollen observation was done using either a confocal or an epifluorescence microscope. The Leica TCS-SP2 confocal microscope was equipped with a $40 \times$ long-distance water immersion objective; the pinhole was set at 1 Airy unit and $488 \mathrm{~nm}$ light from the Ar laser was used to excite both FDA and PI. Emitted fluorescence was recorded at 500-540 nm for FDA and 600-650 nm for PI. Images were recorded as single optical sections at a resolution of $1024 \times 1024$ pixels and included the two fluorescence channels and a bright field image.

The Nikon Eclipse E400 UV-2A fluorescence microscope was equipped with $25 \times$ objective with G-2A (FDA/PI) filter. Images were taken using a Nikon Digital Sight DS-U1 camera and pictures were analyzed with CellProfiler (Bray et al., 2015; Carpenter et al., 2006; Lamprecht et al., 2007). This software is of common use for quantifying cell number, size and morphology; however, the application of CellProfiler in palynology is quite new, so we decided to test its reliability by comparing CellProfiler results with visual analysis of the images.

Pollen grains were scored as viable when showed bright fluorescence. Pollen grains that did not have an intact membrane showed a 

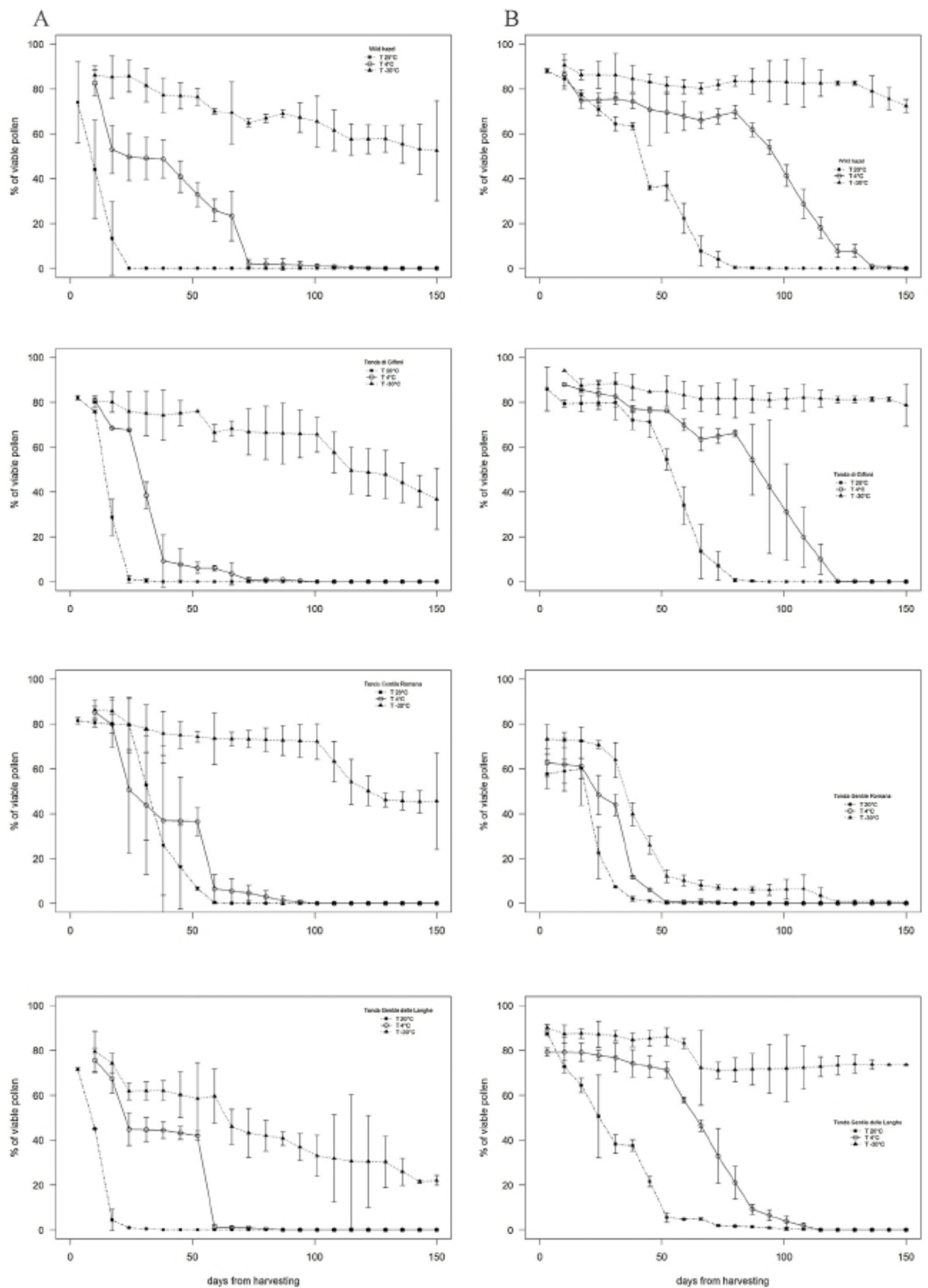

Fig. 1. Viability of pollen grains (\%) of wild hazel and of Tonda di Giffoni, Tonda Gentile Romana and Tonda Gentile delle Langhe, over a 150-day experiment assessed through TTC test under three temperature storage conditions $(20 \cdot \mathrm{C}, 4 \cdot \mathrm{C}$ and $-30 \cdot \mathrm{C})$ during 2015 (A) and 2016 (B). 
uniform background fluorescence, as effect of leakage of fluorescein from membrane, or red color due to the presence of PI.

For all the cultivars and $\mathrm{WH}$ each test was repeated every fifteen-days, for TdG and WH from the 17th to the 66th day from harvesting, for TGR from the 17th to the 94th day from harvesting and for TGdL from the 52nd to the 130th day from harvesting.

\subsection{Statistical analysis}

At least 300 pollen grains were counted for every repetition of each viability test.

For all data, explorative analyses were firstly performed in accordance with Zuur et al. (2009), by using graphical approaches to assess the presence of extreme values and avoid unusual observations that could affect the results of subsequent statistical analyses (Zuur et al., 2009).

The departure from normal distribution (Shapiro test) and homoscedasticity (Levene test) were preventively tested to identify the most appropriate test.

Kruskal-Wallis test was applied to preliminary tests performed to identify the best germination substrate.

The generalized linear models (GLM) procedure was used to analyze the effect of storage temperature, cultivars and their interactions through time on pollen viability. When needed, a zero-inflated, negative binomial model was used to deal with the over-dispersion of the data (glmmADMB package, Fournier et al., 2012; Skaug et al., 2016).

Spearman correlation tests were carried out to verify the agreement between the three different methods used to assess pollen viability.

Finally, the Pearson correlation coefficient was calculated to compare the results of FDA/PI test as obtained by visual estimation and CellProfiler software analysis performed on the same preparation.

All analyses were performed using $\mathrm{R}$ software (RCoreTeam, 2014), version 3.2.3

\section{Results}

\subsection{TTC pollen viability test}

In both years of the study (Fig. 1A, B) the lower temperature of storage $(-30 \circ \mathrm{C})$ represented the best conditions to maintain a high viability level among different cultivars in a long term (Tables 1 and 2).

The results showed some differences among cultivars between the two years of sampling due to interannual variation and the interaction between cultivar and storage condition. For instance, in 2015 at day 100 from harvesting the pollen viability of samples stored at $-30 \cdot \mathrm{C}$ was about $60-65 \%$ in $\mathrm{WH}$ and in $\mathrm{TdG}$, and about $38-40 \%$ in TGdL. In 2016 at the same time, the percentages were generally higher than in 2015 with $80-85 \%$ in $\mathrm{WH}$ and in TdG and about $68-75 \%$ in TGdL. Only TGR showed a lower level of viability (about $8-10 \%$ ) in 2016 compared with the previous year (about $75-80 \%$ ). The different cultivars started the pollen season with different percentages of pollen viability. In particular, cv. TGR and TGdL showed a high degree of variability from year to year. In fact, cv. TGR varied between 80 and $85 \%$ in 2015 instead of $58-75 \%$ in 2016 and the cultivar TGdL varied between 70 and $80 \%$ in 2015 instead of $80-90 \%$ in 2016.

The TTC test provided clear images with easily identification of red and dark-red dyed (viable) (Fig. 2B) and non-dyed (clear) (Fig. 2A).

Finally, the percentage of anomalous pollen differed among cultivars. Anomalous pollen was always non-viable. The higher
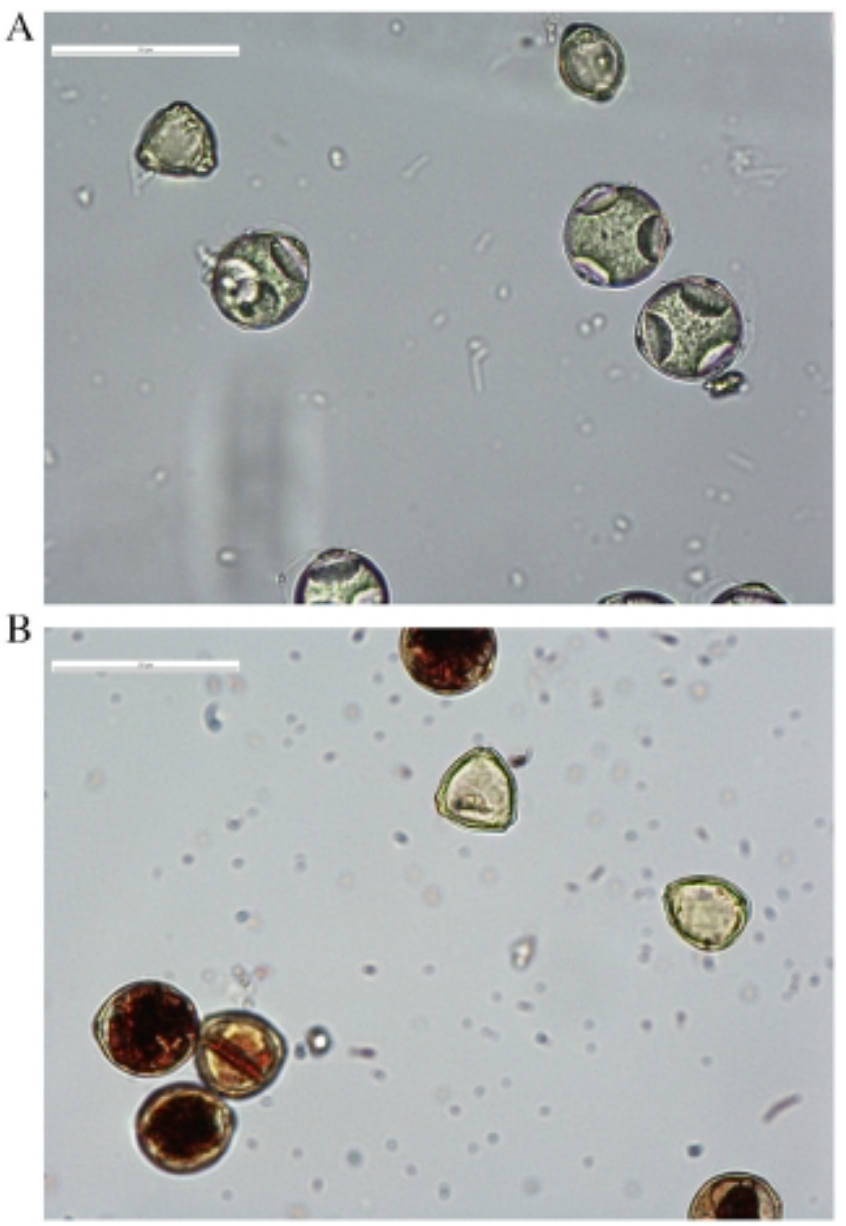

Fig. 2. TTC test: non-viable (normal and anomalous grains) (A), normal viable and anomalous non-viable grains (B).

percentages of anomalous grains were scored in TGdL both in 2015 (mean $36.69 \% \pm 3.87$ ) and in 2016 (mean $41.59 \% \pm 2.58$ ), while the lower percentages were scored in WH both in 2015 (mean $3.15 \% \pm 2.04$ ) and in 2016 (mean $13.44 \% \pm 4.40$ ). In TGR the percentage of anomalous grains was on average of $26.74 \%( \pm 6.06)$ in 2015 and quite higher in $2016(30.49 \% \pm 1.38)$. In $\mathrm{TdG}$ anomalous grains were on average of $26.68 \%( \pm 3.64)$ in 2015 and $28.59 \%( \pm 0.46)$ in 2016.

\subsection{In vitro pollen germination}

The results of preliminary tests showed that there was not significant difference between the three substrates ( $p$-value $=0.07)$. Nevertheless, the Heslop-Harrison germination medium showed a higher mean percentage of germination events $25.34 \% \pm 13.3$ (Brewbacker $19.43 \% \pm 16.3$; Potenza $11.40 \% \pm 6.8$ ) and so it was selected for the following experiments.

The $-30 \cdot \mathrm{C}$ temperature storage condition showed the higher percentage of germinated pollen among all the cultivars (mean $33.15 \%$ ), compared both to $4 . \mathrm{C}$ (mean $4.85 \%$ ) and room temperature $(0.15 \%)$. The lower rate of germination was observed in pollen stored at room temperature $(20 \circ)$. Maximum germination at $-30 \cdot \mathrm{C}(69.53 \%)$ was observed in WH (Fig. 3A) at 45 days from harvesting, and the minimum $(0 \%)$ was observed at $-4 \cdot \mathrm{C}$ in TGR after only 31 days from the collection of pollen and at room temperature from the beginning of the experiments (Fig. 3C).

The germination of TGR remained very low $(0-10 \%)$ for all the study period in all the storage conditions (Fig. 3C). 
Table 1

Parameters of generalized linear model (GLM) fitted on results coming from TTC tests for year 2015. The regression coefficient ( -Estimate), standard error (SE), z statistics and are reported just for significant variables.

\begin{tabular}{|c|c|c|c|c|c|}
\hline Year 2015 & -Estimate & $\mathrm{SE}$ & $\mathrm{z}$ & p-value & \\
\hline Storage $\mathrm{T}-30 \cdot \mathrm{C}$ & -0.66350 & 0.32914 & -2.02 & 0.0438 & * \\
\hline Cultivar TdG & 0.68563 & 0.28711 & 2.39 & 0.0169 & * \\
\hline Cultivar TGR & 3.34365 & 0.31224 & 10.71 & $<0.001$ & $* * *$ \\
\hline Days from harvesting & -0.15481 & 0.01470 & -10.53 & $<0.001$ & $* * *$ \\
\hline Interaction Cultivar $\mathrm{TdG}$ : $\mathrm{T} 4{ }^{\circ} \mathrm{C}$ & -0.95351 & 0.31551 & -3.02 & 0.0025 & $* *$ \\
\hline Interaction Cultivar TGR: $\mathrm{T} 4{ }^{\circ} \mathrm{C}$ & -3.34836 & 0.33361 & -10.04 & $<0.001$ & $* * *$ \\
\hline Interaction Cultivar TGR: $\mathrm{T}-30{ }^{\circ} \mathrm{C}$ & -3.27470 & 0.32645 & -10.03 & $<0.001$ & $* * *$ \\
\hline Interaction Days from harvesting: $\mathrm{T} 4{ }^{\circ} \mathrm{C}$ & 0.10972 & 0.01480 & 7.41 & $<0.001$ & $* * *$ \\
\hline Interaction Days from harvesting: $\mathrm{T}-30 \cdot \mathrm{C}$ & 0.15182 & 0.01468 & 10.34 & $<0.001$ & $* * *$ \\
\hline Interaction Cultivar TGdL: Days from harvesting & -0.00581 & 0.00162 & -3.59 & 0.0003 & $* * *$ \\
\hline
\end{tabular}

Table 2

Parameters of generalized linear model (GLM) fitted on results coming from TTC tests for year 2016. The regression coefficient ( -Estimate), standard error (SE), z statistics and p-value are reported just for significant variables.

Days from harvesting

Interaction Cultivar TGR: T-30 ${ }^{\circ} \mathrm{C}$

Interaction Cultivar TGdL: $\mathrm{T}-30{ }^{\circ} \mathrm{C}$

Interaction Days from harvesting: $\mathrm{T} 4 \mathrm{\circ} \mathrm{C}$

Interaction Days from harvesting: $\mathrm{T}-30 \circ \mathrm{C}$

Interaction Cultivar TGR: Days from harvesting

Interaction Cultivar TGdL: Days from harvesting

$\begin{array}{llll}-0.04491 & 0.00284 & -15.80 & <0.001 * * * \\ 0.83647 & 0.28093 & 2.98 & 0.0029 * * \\ 0.44466 & 0.21660 & 2.05 & 0.0401 * \\ 0.02409 & 0.00298 & 8.07 & <0.001 * * * \\ 0.04584 & 0.00281 & 16.29 & <0.001 * * * \\ -0.03439 & 0.00347 & -9.92 & <0.001 * * * \\ -0.00414 & 0.00170 & -2.44 & 0.0148 *\end{array}$

A

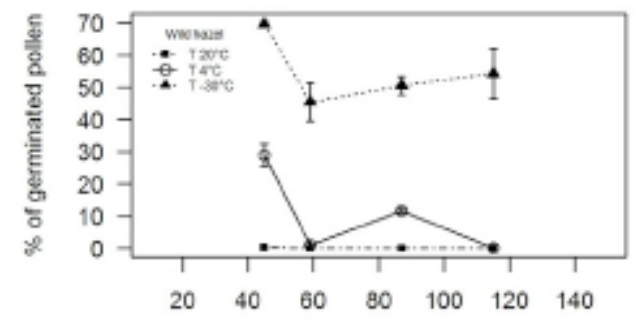

C

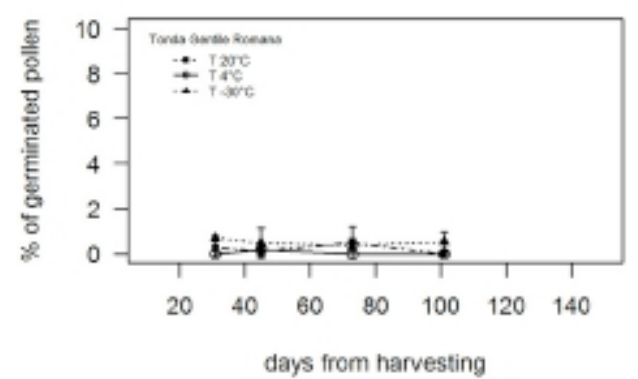

$\mathrm{B}$

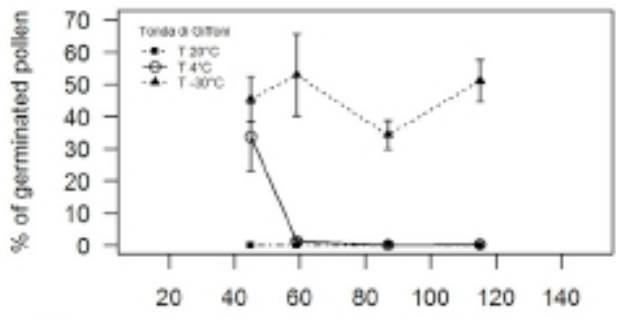

D

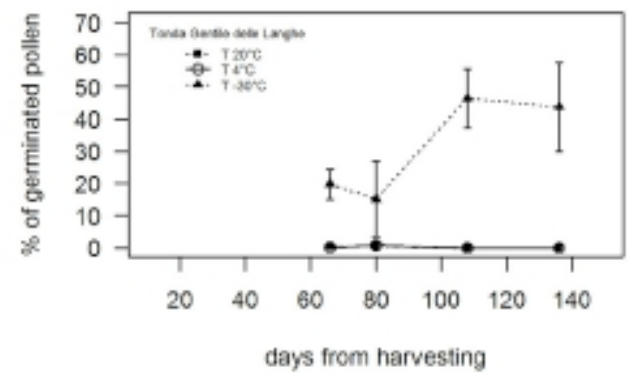

Fig. 3. Germination of pollen grains (\%) of wild hazel (A), Tonda di Giffoni (B), Tonda Gentile Romana (C) and Tonda Gentile delle Langhe (D), assessed through in-vitro pollen germination test under three storage conditions $(20 \cdot \mathrm{C}, 4 \cdot \mathrm{C}$ and $-30 \cdot \mathrm{C})$.

\subsection{FDA/PI viability test}

The viability estimated through the CellProfiler software showed the maintenance of high values (between 65 and $85 \%$ ) in TGR during all the experiment and in all the temperature storage conditions (Fig. 4A), as in the other cultivars. The viability estimated by visual analysis showed a decreasing trend and the maintenance of higher values in the $-30 \cdot \mathrm{C}$ storage condition (Fig. 4B). Comparison of data coming from all cultivars and WH by CellProfiler software and visual analysis (Fig. 5A) confirms that the first method shows the maintenance of higher values on average. There is a medium correlation between the two analyses (Fig. 5B).
In both visual and CellProfiler analysis, the degrees of brightness that varies between images (Fig. 6) determined an ambiguous count of viable and non-viable pollen grains.

\subsection{Correlation between tests}

The correlation analysis between TTC and germination test showed a quite high value ( $=0.78$, p-value $\left.<0.001^{* * *}\right)$. On the contrary, the correlation between TTC and FDA/PI test, both with visual estimation ( $=0.56$, p-value $\left.<0.001^{* * *}\right)$ and CellProfiler software analysis $\left(=0.42\right.$, p-value $\left.=0.004^{* * *}\right)$, was lower. 

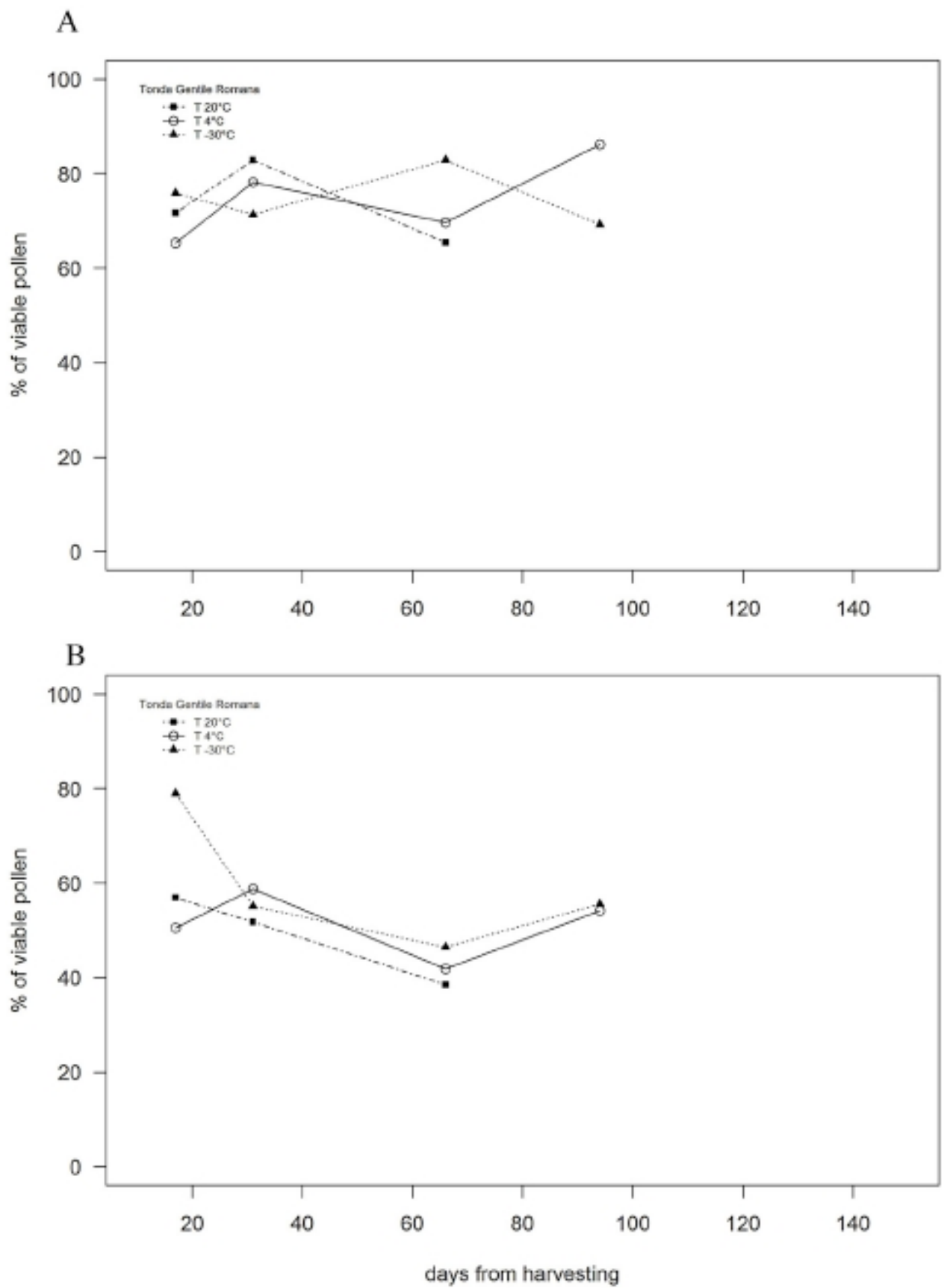

Fig. 4. Viability of Tonda Gentile Romana (\%) stored at $20{ }^{\circ} \mathrm{C}, 4{ }^{\circ} \mathrm{C}$ and $-30{ }^{\circ} \mathrm{C}$ through FDA/PI test obtained by CellProfiler analysis (A) and visual analysis (B).

The Spearman correlation test showed a low correlation between germination and FDA/PI test (Visual analysis: $=0.14, \mathrm{p}$ value $=0.66$; CellProfiler analysis: $\quad=0.41, \mathrm{p}$-value $=0.17)$.

\section{Discussion}

The results obtained in this study from different viability tests demonstrated that the best temperature condition for long term storage was at $-30 \circ \mathrm{C}$. This temperature represents the most convenient storage strategy for efficient conservation of pollen viability for artificial or supplementary pollination, as the pollen maintained a high level $(>40-50 \%)$ of viability at 150 days from harvesting in both years. This result clearly emerged despite the differences observed between cultivars and years.
Indeed, the experiments highlighted a certain degree of variability for each cultivar in terms of loss of viability through time, depending on the storage conditions. The pollen viability may differ between years, as observed for TGR and TGdL. This phenomenon can be attributed to different causes, as referred in literature also for other cultivated species: unfavorable time of pollen harvesting, genotype, "on" or "off" year for the yield (i.e. olive), type of twigs, environmental stress (Ferrara et al., 2007; Asma, 2008; Calic et al., 2013; Mazzeo et al., 2014; Gallotta et al., 2014; Soares et al., 2015). Moreover, the analyses revealed a combined effect of cultivar and temperature storage on pollen viability.

Furthermore, the absolute estimate of viability differed among methods, because each method is affected by different variables (Dafni and Firmage, 2000). 

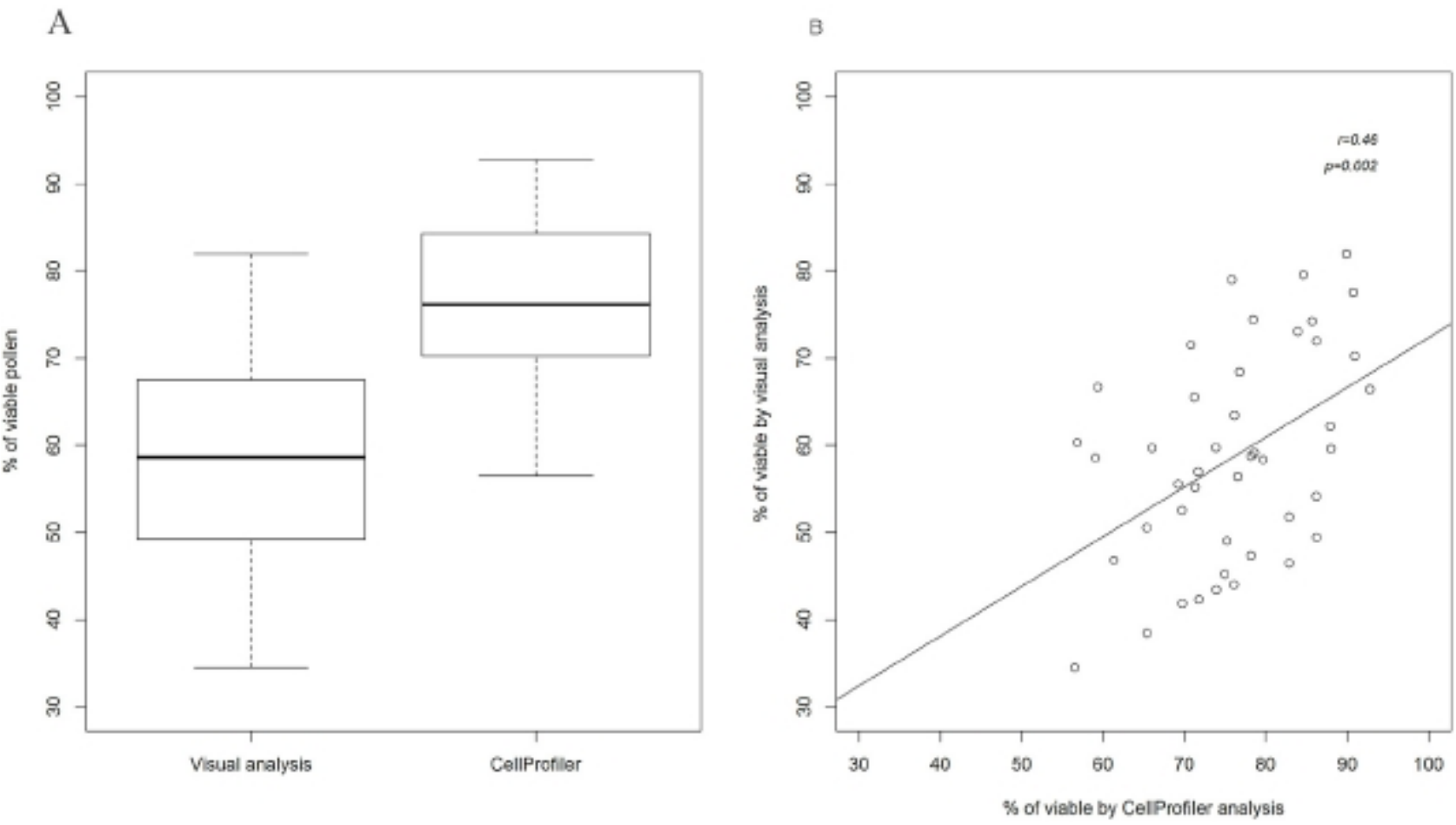

Fig. 5. Comparison between the results obtained by visual and CellProfiler analysis in boxplot showing the difference in percentage of viable pollen (A) and correlation of results obtained by the two methods (B).

A

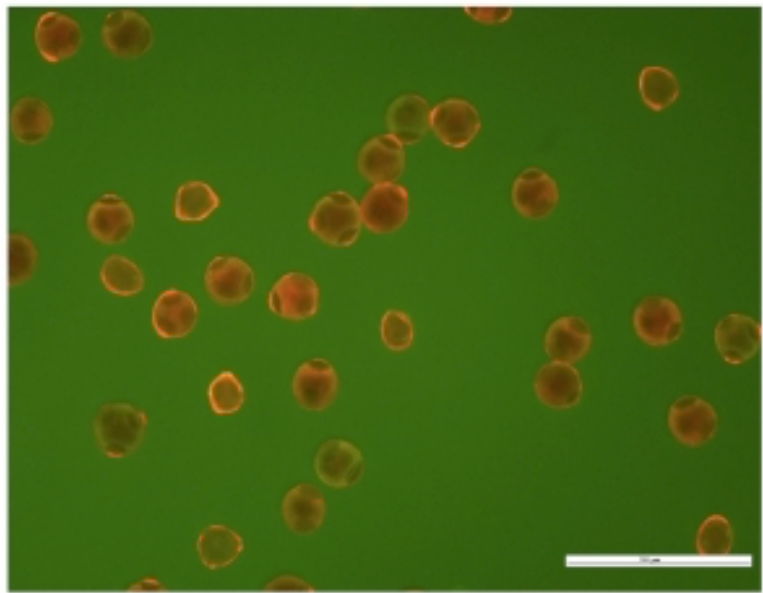

C

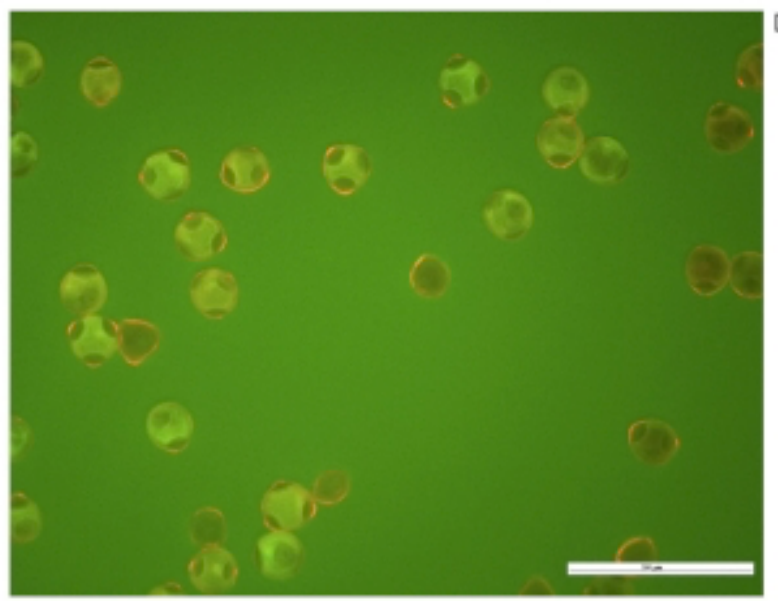

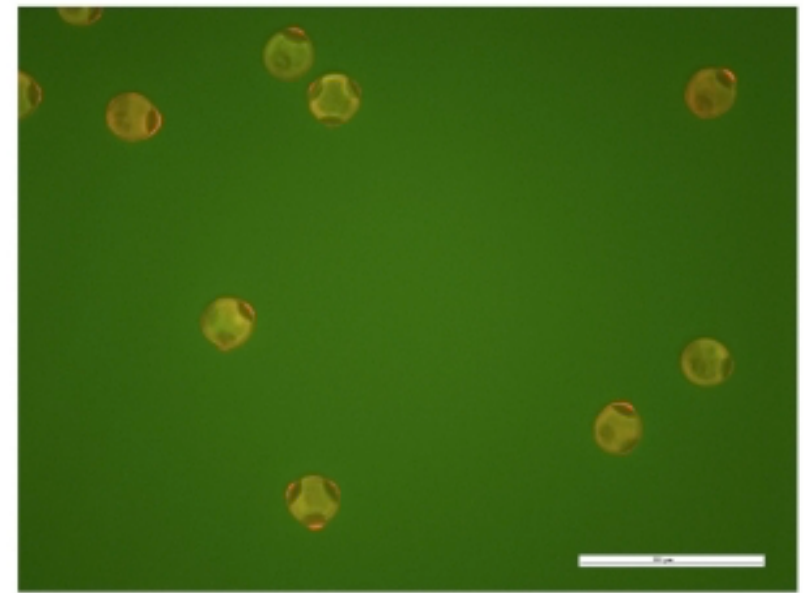

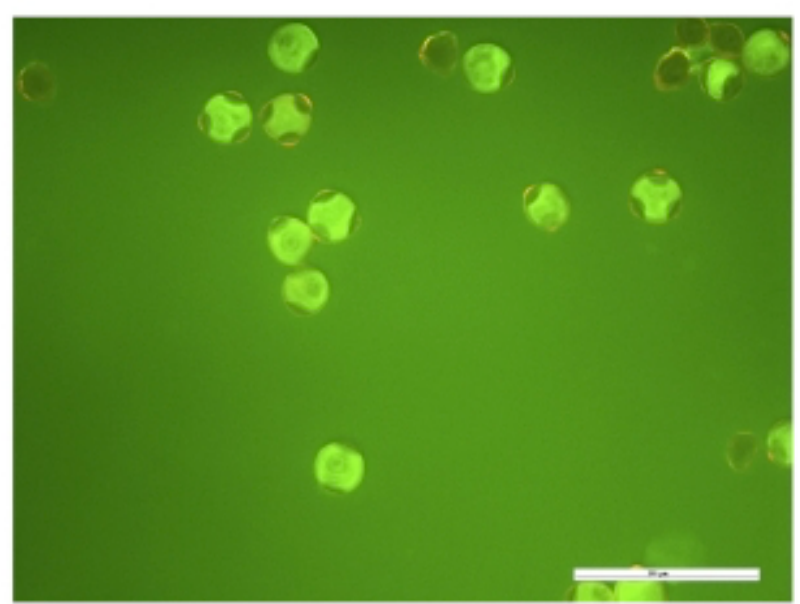

Fig. 6. Fluorescein diacetate test (FDA/PI): non-fluorescent pollen grains (A), fluorescent and non-fluorescent pollen grains (B, C) and fluorescent pollen grains (D). 
As referred in the literature (Heslop-Harrison et al., 1984; Sedgley and Harbard, 1993; Shivanna, 2003), TTC overestimates the pollen viability because the dye of pollen shows a gradation in color intensity that can affect the objectivity of estimate. Moreover, this method highlights as viable all the pollen grains in which the dehydrogenase activity is present and even if there is a correlation between TTC and germination, the germination values are always notably lower. Conversely, the lack of a specific protocol to assess the germinability of hazel pollen leads to false negative results (Shivanna, 2003). The in-vitro pollen grain germination provides a controlled experimental system, but it does not fully reproduce the in-vivo pollen tube growth, where interactions between the pollen and the stigma surface are more complex. Nevertheless, both TTC and in vitro pollen germination, agree in highlighting that the $-30 \cdot \mathrm{C}$ storage temperature represented the best conditions to maintain a high viability level.

Since the FDA/PI method tests two aspects of viability, the enzymatic activity and the intactness of cell membrane, it measures the potential for germination, rather than germinability, so it may overestimate viability (Shivanna and Heslop-Harrison, 1981). Therefore, the present study confirmed the very low correlation between FDA/PI, in-vitro germination and TCC tests as referred in literature (Sato et al., 1998). Furthermore, the microscope observations of FDA/PI have to be carried out rapidly because the fluorescence decades quickly and the various degree of fluorescence intensity affects the interpretations of the results (Khatum and Flowers, 1995) (Fig. 6). For this reason, new analyses of images coming from fluorescent microscopy, i.e. the CellProfiler software, should be implemented, in order to increase the objectivity of the counts. Nevertheless, many difficulties in image interpretation remain also with automated methods, as demonstrated by the low correlation between visual estimation and CellProfiler analysis of hazel pollen viability observed in the present study (Fig. 5B).

Therefore, the simultaneous use of several tests should be supported in order to evaluate the different features of pollen viability (Dafni and Firmage, 2000; Rodriguez-Riano and Dafni, 2000; Thomson et al., 1994). New applications of microfluidic impedancebased flow cytometry (Cheung et al., 2010; David et al., 2012) are highly promising for the evaluation of pollen viability and have to be considered also for direct applications in agriculture.

The effect of rehydration before testing can have a positive influence on pollen viability, as referred in literature (Heslop-Harrison and Heslop-Harrson, 1993; Pacini et al., 1997). High humidity status represents the most similar condition to what probably occurs in vivo, where the pollen meets the humid surface on the stigma (Edlund et al., 2004), and the loss of pollen viability in several species has been correlated with water loss (Hanna and Towill, 1995; Heslop-Harrison and Heslop-Harrison, 1985).

Finally, the presence of different percentages of anomalous pollen, which origin is still poorly investigated, among cultivars and wild type should be considered when a pollinizer is selected for artificial or supplementary pollination.

\section{Conclusion}

The present study demonstrated that $-30{ }^{\circ} \mathrm{C}$ storage temperature is the best condition, among those tested here, for a long term storage of hazel pollen. The methods used to assess the pollen viability can affect the results and leads biased estimates of pollen viability. So, simultaneous tests can provide different information on the pollen viability and germinability during storage. TTC resulted the most convenient and easy to use method in obtaining a rapid evaluation of hazel pollen viability.

The results obtained can have a useful application for supplementary pollination: the pollen, which can be easily collected in high amounts due to the abundant production in hazel, if stored at $-30 \circ \mathrm{C}$, maintains, also after 5 months, sufficient viability percentages to be used efficiently to increase yield production when the pollinizers are not sufficient or in young orchards. In difficult environmental or agronomic conditions, preliminary and promising results with increasing yields were obtained after the use of supplementary pollination.

\section{Acknowledgements}

The research was carried out with the contribution of Ferrero Hazelnut Company and has been funded by a grant of Istituto Nazionale della Previdenza Sociale (INPS) in the context of the $\mathrm{PhD}$ in Biology and Applied Biotechnologies in the thesis entitled "Influence of environmental factors on reproductive biology in hazelnut (Corylus avellana L.).

\section{References}

Asma, B.M., 2008. Determination of pollen viability, germination ratios and morphology of eight apricot genotypes. African J. Biotechnol. 7 (23).

Bray, M.A., Vokes, M.S., Carpenter, A.E., 2015. Using CellProfiler for automatic identification and measurement of biological objects in images. Curr. Protoc. J. Mol. Biol. 109 (14.17. 1-14.17.13).

Brewbaker, J.L., Kwack, B.H., 1963. The essential role of calcium ion in pollen germination and pollen tube growth. Am. J. Bot. 50 (9), 859-865.

Carpenter, A.E., Jones, T.R., Lamprecht, M.R., Clarke, C., Kang, I.H., Friman, O., Guertin, D.A., Chang, J.H., Lindquist, R.A., Moffat, J., Golland, P., Sabatini, D.M. 2006. CellProfiler: image analysis software for identifying and quantifying cell phenotypes. Genome Biol. 7 (10), R100

Calić, D., Devrnja, N., Kostić, I., Kostíc, M., 2013. Pollen morphology, viability, and germination of Prunus domestica cv. Pozegaca. Scientia Horticulturae 155, $118-122$.

Cheung, K.C., Di Berardino, M., Schade-Kampmann, G., Hebeisen, M., Pierzchalski, A., Bocsi, J., Mittag, A., Tárnok, A., 2010. Microfluidic impedance-based flow cytometry. Cytometry 77, 648-666.

Črepinsěk, Z., Stampar, F., Kajfez-Bogataj, L., Solar, A., 2012. The response of Corylus avellana L. phenology to rising temperature in north-eastern Slovenia. Int. J. Biometeorol. 56, 681-694.

Dafni, A., Firmage, D., 2000. Pollen viability and longevity: practical, ecological and evolutionary implications. Plant Systematics Evolut. 222 (1), 113-132.

David, F., Hebeisen, M., Schade, G., Franco-Lara, E., Di Berardino, M., 2012. Viability and membrane potential analysis of Bacillus megaterium cells by impedance flow cytometry. Biotechnol. Bioeng. 109, 483-492.

Deng, Z., Harbaugh, B.K., 2004. Technique for in vitro pollen germination and short-term pollen storage in caladium. HortScience 39 (2), 365-367.

Dutta, S.K., Srivastav, M., Chaudhary, R., Lal, K., Patil, P., Singh, S.K., Singh, A.K., 2013. Low temperature storage of mango (Mangifera indica L.) pollen. Sci. Hort. 161, 193-197.

Edlund, A.F., Swanson, R., Preuss, D., 2004. Pollen and stigma structure and function: the role of diversity in pollination. Plant Cell 16 (Suppl), S84-S97.

Ellena, M., Sandoval, P., Gonzalez, A., Galdames, R., Jequier, J., Contreras, M., Azocar, G., 2014. Preliminary results of supplementary pollination on hazelnut in South Chile. Acta Hortic. 1052, 121-127

Ferrara, G., Camposeo, S., Palasciano, M., Godini, A., 2007. Production of total and stainable pollen grains in Olea europaea L. Grana 46, 85-90.

Food, Agriculture Organization of the United Nations, 2011. Food and Agricultural Commodities Production., pp. 2011 (28 December) http://faostat.fao.org/site/ 339/default.aspx.

Fournier, D.A., Skaug, H.J., Ancheta, J., Ianelli, J., Magnusson, A., Maunder, M., Nielsen, A., Sibert, J., 2012. AD Model Builder: using automatic differentiation for statistical inference of highly parameterized complex nonlinear models. Optim. Methods Softw. 27, 233-249.

Gallotta, A., Palasciano, M., Mazzeo, A., Ferrara, G., 2014. Pollen production and flower anomalies in apricot (Prunus armeniaca L.) cultivars. Sci. Hort. 172, 199-205.

Hanna, W.W., Towill, L.E., 1995. In: Janick, J. (Ed.), Long-Term Pollen Storage, in Plant Breeding Reviews, Vol. 13. John Wiley \& Sons, Inc Oxford.

Heslop-Harrison, J., Heslop-Harrison, Y., 1985. Germination of stress-tolerant Eucalyptus pollen. J. Cell Sci. 73, 135-157.

Heslop-Harrison, J., Heslop-Harrson, Y., 1993. Vapor phase activation, intracellular motility and germination in the triporate pollen of Epilobium angustifolium. Botanica Acta 106, 331-337.

Heslop-Harrison, J., Heslop-Harrison, Y., Shivanna, K.R., 1984. The evaluation of pollen quality and a further appraisal of the fluorochromatic (FCR) test procedure. Theor. Appl. Genet. 67, 367-375.

Heslop-Harrison, J., 1988. Pollen germination and pollen tube growth. Int. Rev. Cytol. 107, 1-78.

Khatum, S., Flowers, T.J., 1995. The estimation of pollen viability in rice. J. Exp. Bot. 46, 151-154. 
Lamprecht, M.R., Sabatini, D.M., Crpenter, A.E., 2007. CellProfiler: free, versatile software for automated biological image analysis. Biotechniques 42 (1), 71-75.

Mazzeo, A., Palasciano, M., Gallotta, A., Camposeo, S., Pacifico, A., Ferrara, G., 2014 Amount and quality of pollen grains in four olive (Olea europaea L.) cultivars as affected by 'on' and 'off' years. Sci. Hort. 170, 89-93.

Mehlenbacher, S.A., 1991. Hazelnuts (Corylus). Acta Hortic. 290, 791-829.

Mehlenbacher, S.A., 2014. Geographic distribution of incompatibility alleles in

cultivars and selections of european hazelnut. J. Am. Soc. Hortic. Sci. 139, $191-212$

Novara, C., Falzoi, S., La Morgia, V., Spanna, F., Siniscalco, C., 2016. Modelling the pollen season start in Corylus avellana and Alnus glutinosa. Aerobiologia 31 (4), $1-15$.

Pacini, E., Franchi, G.G., Lisci, M., Nepi, M., 1997. Pollen viability related to type of pollination in six angiosperm species. Ann. Bot. 80, 83-87.

Potenza, A., Caramiello, R., Me, G., 1994. 'TGL', Cosford and hybrids TGL x Cosford pollen viability and germinability. Acta Hortic. 351, 270-275.

R Core Team, 2014. R: A Language and Environment for Statistical Computing. R Foundation for Statistical Computing, Vienna, Austria, http://www.R-project. org/. Last Accessed July 2016.

Rodriguez-Riano, T., Dafni, A., 2000. A new procedure to assess pollen viability. Sexual Plant Reprod. 12, 242-244.

Sato, S., Katoh, N., Iwai, S., Hagimori, M., 1998. Establishment of reliable methods of in vitro pollen germination and pollen preservation of Brassica rapa (syn. B. campestris). Euphytica 103 (1), 29-33.

Sedgley, M., Harbard, J.L., 1993. Pollen storage and breeding system in relation to controlled pollination of four species of Acacia. Aust. J. Bot. 41, 601-609.

Shivanna, K.R., Heslop-Harrison, J., 1981. Membrane state and pollen viability. Ann. Bot. 47 (6), 759-770.
Shivanna, K.R., Rangaswamy, N.S., 1992. Pollen Biology: A Laboratory Manual. Springer Berlin, Heidelberg, New York.

Shivanna, K.R., 2003. Pollen Biology and Biotechnology. Science Publishers, Inc., Enfield, NH, USA (Printed in India).

Singh, S.P., Singh, S.P., Pandey, T., Singh, R.R., Sawant, S.V., 2015. A novel mal sterility-fertility restoration system in plants for hybrid seed production. Sci. Rep. 5.

Skaug, H., Fournier, D., Bolker, B., Magnusson, A., Nielsen, A., 2016. Generalized Linear Mixed Models Using 'AD Model Builder' (R package version 0.8.3.3).

Soares, T.L., de Jesus, O.N., de Souza, E.H., de Oliveira, E.J., 2015. Reproductive biology and pollen-pistil interactions in Passiflora species with ornamental potential. Sci. Hort. 197, 339-349.

Stanley, R.G., Linskens, H.F., 1974. Pollen: Biology, Biochemistry and Management Springer New York

Thompson, M.M., 1979a. Genetics of incompatibility in Corylus avellana L. Theor Appl. Genet. 54, 113-116.

Thompson, M.M., 1979b. Incompatibility alleles in Corylus avellana cultivars. Theor. Appl. Genet. 55, 29-33.

Thomson, J.D., Rigney, L.P., Karoly, K.M., Thomson, B.A., 1994. Pollen viability, vigor, and competitive ability in Erythronium grandiflorum (Liliaceae). Am. J. Bot. 81, $1257-1266$.

Wang, L., Wu, J., Chen, J., Fu, D., Zhang, C., Cai, C., Ou, L., 2015. A simple pollen collection, dehydration, and long-term storage method for litchi (Litchi chinensis Sonn.). Sci. Hort. 188, 78-83.

Zuur, A.F., Ieno, E.N., Walker, N.J., Savaliev, A.A., Smith, G.M., 2009. Mixed Effect Models and Extensions in Ecology with R. Springer Berlin, pp. 574. 